\title{
Numerical Feasibility Study of a Wax Cold Flow Approach for Subsea Tie-In Flowlines Using a 1D Mechanistic Multiphase Flow Simulator
}

\author{
Diana González, Milan Stanko, Michael Golan \\ Department of Geoscience and Petroleum-NTNU, Trondheim, Norway \\ Email: diana.rengifo@ntnu.no
}

How to cite this paper: González, D., Stanko, M. and Golan, M. (2018) Numerical Feasibility Study of a Wax Cold Flow Approach for Subsea Tie-In Flowlines Using a 1D Mechanistic Multiphase Flow Simulator. Engineering, 10, 109-123. https://doi.org/10.4236/eng.2018.103008

Received: March 2, 2018

Accepted: March 26, 2018

Published: March 29, 2018

Copyright $\odot 2018$ by authors and Scientific Research Publishing Inc. This work is licensed under the Creative Commons Attribution International License (CC BY 4.0).

http://creativecommons.org/licenses/by/4.0/

\begin{abstract}
This work is a thermo-fluid numerical case study to investigate the size and performance of a system that eliminates needs for insulating, heating and inhibiting chemically the deposition of wax in subsea tie-in flowlines. For short, we call this type of systems "Cold Flow". The particular system analyzed in this study consists of a reactor unit at the inlet to the flowline, where the thermal solubility of the wax-creating molecules is reduced by cooling. Subsequently, solid wax is deposited in the reactor piping and wax free crude is entering the flowline. The reactor is regenerated periodically. The reactor-pipeline system was modelled using a commercial flowline simulator, with transient, thermal, multiphase and deposition capabilities. The basic layout used was a transportation pipeline of $8 \mathrm{~km}$ and 6.69 in ID with a mass flow rate of $17.51 \mathrm{~kg} / \mathrm{s}$, a water cut (WC) of zero and an inlet temperature of $70^{\circ} \mathrm{C}$. The wax appearance temperature (cloud point) of the crude is $22^{\circ} \mathrm{C}$ and the seabed temperature is $4^{\circ} \mathrm{C}$. Three types of reactors have been simulated: a non-insulated pipe section, a passive cooler with a bundle of parallel pipes and an active cooler. Sensitivity analyses have been performed for all three cases varying the external convective coefficient, the reactor pipeline diameter and the WC. For a non-insulated pipeline section cooler, the required length is of the same order of magnitude as the main flowline, implying that such a solution is impractical for short flowline distances or when a compact deployment is desired. For the passive cooler case, the required length was half of that in the previous case; thus it is still significant. For the active cooler reactor, the required cooling duty was $2.2 \mathrm{MW}$. In all three cases, the pipe-flow dynamics were analyzed, and the pigging arrangement complexity has been qualitatively addressed. However, the detailed design falls out of the scope of this study.
\end{abstract}

\section{Keywords}

Cold Flow, Wax Deposition, Flow Assurance, Wax Modelling, 1D Simulation 


\section{Introduction}

Tie-in of satellite subsea fields to offshore processing facilities or tie-back of subsea fields directly to shore is very attractive solutions to save costs and offshore complexities. However, the untreated streams of oil, gas and water impose severe flow assurance challenges for the pipe flow. Wax deposition, which increases pressure drop and can ultimately cause pipe blockage, is one of the challenges addressed in this work. One of the approaches to overcome wax deposition is to extract, from the fluid stream, the wax-creating material before entering the flowline, a concept commonly known as "Cold Flow".

To the authors' knowledge, the idea of Cold Flow comes from the work of Coberly [1], who showed that the presence of solid particles in the bulk fluid decreases the tendency of wax crystals to deposit. Various concepts of Cold Flow have been presented in the literature and some have also been registered in patents. Merino-Garcia \& Correa presented a review of existent patents that use Cold Flow technologies for the control of wax deposition [2]. Furthermore, Al-Yaari reviewed wax deposition problems in flow assurance and addressed techniques for wax deposition mitigation [3]. Both authors mention the following equipment for wax control:

- The wax eater (Kellog, Brown and Root, Halliburton) [4] [5];

- Cold seeding (NEI, Calgary, Canada and Marathon Oil, Houston, Texas) [6];

- High-shear heat exchanger (Kellog, Brown and Root, Halliburton) [5];

- Pressure surge (Kellog, Brown and Root, Halliburton) [5];

- Flash cooling (Shell Western E\&P Inc., Houston, Texas) [7];

- Oil or solvent injection (C-Fer Technologies, Edmonton, Canada);

- Magnetic conditioning (Magwell. Boerne, Texas, and Halliburton).

Cold flow can also be applied to handle gas hydrates and several technologies have been developed [8]: Anti-agglomerate; the SINTEF cold flow technology [9]; the NTNU cold flow hydrate technology [10]; and HYDRAFLOW [11]. Watson, Speranza, \& LaCombe, performed a study comparing these four technologies, highlighted possible obstacles that need to be overcome and showed the effect in the production profile for a specific system [8]. Akpabio and Vinatovskaja, performed comparison studies of three cold flow technologies for gas hydrate mitigation (SINTEF, NTNU and HYDRAFLOW) against conventional technologies (injection of inhibitors and direct electrical heating). Both concluded that Cold Flow technologies offer a better solution for the flow assurance problems in deep-water and arctic environment, and are especially suited for long distances [12] [13].

Wax is a solid formation and deposition in production flowlines that can cause flow assurance issues. Wax crystals appear in the production bulk flow as a result of temperature and pressure changes along the production system. When oil is transported, there is a temperature gradient between the pipe wall and the bulk flow, which can make the fluid temperature drop below the so-called Wax Appearance Temperature (WAT). This WAT, also known as Cloud Point, is the 
temperature below which wax precipitates. After precipitation, wax may deposit in the pipe walls, leading to increase in the pressure drop, decrease in flow rate and clogging of pipelines.

Conventional wax and hydrate mitigation methods are chemical, thermal and mechanical management. The chemical management consists in the injection of inhibitors into the pipeline [14], this solution is suitable for long tieback distance systems. However high concentrations of inhibitor are usually required, thus this solution is not always cost effective. Thermal management can be of two types, passive and active. The passive thermal management consists in insulate the pipeline, however it is not effective for long transportation distances since the fluid is still cooling while it flows along the pipeline. The active thermal management is electrical heating. It consists in keeping the temperature of the fluid above the wax appearance temperature. The drawbacks of this technology are its cost and electrical power distribution over long distances [14]. The mechanical management consists in carrying on regular pigging to clean the pipeline. However, it is also costly for long transportation distances, because it requires either, two parallel flowlines, to send and received the pig from the same place, or a subsea pig launcher activated with a marine vessel. Additionally, pigs can be stuck and block the pipeline causing massive production losses [14].

Due to the problems associated with wax deposition in production pipelines, the oil industry makes important efforts in the understanding of this phenomenon. One way of understanding, is through numerical models that can predict where and how wax builds up, how the pressure drops and how often wax has to be removed. These models are based on the most relevant wax deposition mechanism, usually molecular diffusion and shear dispersion. Transient multiphase flow simulators, like OLGA [15], have the capability of simulating wax deposition using wax models. The wax deposition models found in OLGA are: RRR, Matzain and Heatanalogy. Wax modelling is of particular importance in the evaluation of cold flow technologies.

This paper is focused on studying a wax cold flow concept [4] [5], which consists of inducing by cooling, the formation, precipitation and deposition of wax in a section of the production system. This section is then periodically "cleaned" and the inert wax particles sent together with the production fluids. The present work performs a simplified feasibility study of this idea using the commercial multiphase simulator OLGA and a synthetic production system that represents a typical oil field in the North Sea. Three main cases were analyzed. The first one consists of a non-insulated pipe section cooled by sea currents. The aim was to determine the influence of parameters like the pipeline diameter, the overall heat transfer coefficients and watercuts (WC), in the required cooling length of the pipe section. The second case consists on installing a passive cooler with a bundle of parallel pipes cooled by sea currents. Sensitivity runs were made by trying several numbers of parallel segments and several parallel segments length. The third case consists on installing an active cooler. The required duty to guarantee 
thermal equilibrium between the production fluids and the surroundings was calculated. That the rheology of the waxy crude was neglected in the present study.

The main contribution of this study is the simplified technical validation of a wax cold flow concept in a synthetic case of a subsea oil flowline. The validation consisted of performing a numerical estimation of required cooling distances and performance of three (3) cooling arrangements. Observations are then provided regarding the applicability of the method in a real system.

This work will hopefully contribute to the further maturing of cold flow concepts that are proposed by the industrial and scientific community to deal with wax accumulation problems in subsea flowlines.

\section{Wax Deposition Mechanisms}

There are several models proposed in the literature to predict the deposition of wax in a pipeline [16]. Models typically consider four mechanisms: molecular diffusion, Brownian diffusion, shear dispersion and gravity settling [17]. However, the two mechanisms most widely used are molecular diffusion and shear dispersion and will be described briefly next.

\subsection{Molecular Diffusion}

When the wall reaches the wax appearance temperature, the wax starts to precipitate in the region closest to the wall. Thus, a concentration gradient is created between the wax dissolved in the bulk flow and the wax in solution close to the wall. A molecular diffusion process then occurs when the wax dissolved in the bulk flow is diffused toward the pipe wall where it precipitates. Based on the results of Bern et al. and Brown, Niessen \& Erickson, molecular diffusion is the principal responsible for wax deposition [18] [19]. This is especially valid for systems at high temperatures and high heat flux conditions [17].

\subsection{Shear Dispersion}

While the wax particles are suspended in the flowing oil, they tend to move in the same direction and speed of the flow. Due to the velocity gradient, shear is greater in the proximities of the pipe wall, so the particles tend to move towards the center of the pipe. This effect usually causes the transport of the precipitated wax to be predominantly far from the wall. Brown, Niessen \& Erickson [19], discusses that laboratory evidence indicates that the effect of shear dispersion is not significant in comparison with molecular diffusion. Additionally, Bern, Withers \& Cairns [18] and Burger, Perkins \& Striegler [17], state that the shear dispersion is dominant when flow is at low temperature and low heat flux, and when there is a high concentration of wax crystals in the flow.

\section{Wax Deposition Modelling in OLGA}

In this section the models that are available in the commercial software OLGA to 
predict wax deposition are described.

OLGA has a wax deposition module to model wax precipitation and deposition. The calculation is made based on a pre-calculated table that contains information of each wax-forming component [15]. This table has information like the number and name of wax components, their molecular weights, liquid densities, cloud point temperatures, concentration of wax components in HC mixture, etc. OLGA uses the table as an input file for the calculation of wax deposition. The simulator has three models for wax deposition. They are RRR (Rygg, Rygdahl and Rønningsen) model, Matzain model and HEATANALOGY model.

\subsection{RRR (Rygg, Rydahl and Rønningsen) Model}

The RRR model is a wax deposition model for multiphase flow in pipelines. Rygg, Rydahl and Rønningsen created this model in 1998 [16]. It takes into account both molecular diffusion and shear dispersion effects. In the model, wax deposition affects the pressure drop since it decreases the pipe diameter. In addition, it influences the heat exchange of the fluids with the environment, because the wax acts as an insulation layer between the wax bulk flow and the pipe wall. The increase in the thickness of the wax layer is a volume rate calculated as the sum of the contribution of molecular diffusion and shear dispersion:

$$
l_{\max }=\frac{V o l_{\text {wax }}^{\text {diff }}+V o l_{\text {wax }}^{\text {shear }}}{(1+\phi) 2 \pi r L}
$$

where $l_{\max }$, is the rate of increase in thickness for the wax layer $(\mathrm{m} / \mathrm{s}) . \phi$, is the wax porosity, it can be used as a tuning parameter in OLGA [15]. $r$, is current inner pipe radius $(\mathrm{m}) . L$, is the length of the pipe section $(\mathrm{m}) . \operatorname{Vol}_{\text {wax }}^{\text {diff }}$, is the volume rate of wax deposition by molecular diffusion $\left(\mathrm{m}^{3} / \mathrm{s}\right) . V_{\text {wax }}$, is the volume rate of wax deposition by shear dispersion $\left(\mathrm{m}^{3} / \mathrm{s}\right)$.

The two volume rates of wax deposition terms are calculated with the following equations:

By molecular diffusion (function of composition)

$$
\operatorname{Vol}_{\text {wax }}^{\text {diff }}=\sum_{i}^{N \max } \frac{D_{i}\left(c_{i}^{b}-c_{i}^{w}\right) S_{\text {wet }} M W_{i}}{\delta \rho_{i}} 2 \pi r L
$$

where $c_{i}^{b}, c_{i}^{w}$ are the molar concentration of the wax component $i$, dissolved in the bulk oil phase and at the wall, respectively $\left(\mathrm{mol} / \mathrm{m}^{3}\right) . S_{\text {wet }}$, is the fraction of wetted circumference. $N_{\max }$, is the number of wax components. $M W_{i}$, is molar weight of wax component $i(\mathrm{~kg} / \mathrm{mol}) . \rho_{i}$, is density of the wax component $i\left(\mathrm{~kg} / \mathrm{m}^{3}\right) . D$, is the diffusion coefficient $\left(\mathrm{m}^{2} / \mathrm{s}\right) . \delta$, is the thickness of the laminar sublayer $(\mathrm{m})$.

In OLGA, the diffusion coefficient $D$ is calculated with Hayduk-Minhas correlation [15].

By shear dispersion (Burger, Perkins \& Striegler correlation, 1981 [17])

$$
V_{\text {ol }}^{\text {whear }}=\frac{k^{*} C_{\text {wall }} \dot{\gamma} A}{\rho_{\text {wax }}}
$$


where $k^{*}$, is the shear deposition rate constant $\left(\mathrm{kg} / \mathrm{m}^{2}\right) . C_{\text {wall }}$, is the volume fraction of the precipitated wax in the oil at the inner wall temperature. $\dot{\gamma}$, shear rate at the wall $\left(\mathrm{s}^{-1}\right) . A$, surface area available for deposition $\left(\mathrm{m}^{2}\right) . \rho_{\text {wax }}$, average wax density $\left(\mathrm{kg} / \mathrm{m}^{3}\right)$.

The RRR model does not take into account any removal mechanism. It assumes that all the wax transported to the wall sticks to the surface when the temperature is below the WAT.

\subsection{Matzain Model}

The Matzain is a semi-empirical kinetic model that predicts wax thickness based on experimental tests conducted on South Pelto oil in the Gulf of Mexico [16]. The model takes into account shear stripping alongside molecular diffusion and shear dispersion as wax deposition mechanisms. The shear stripping is a wax reducing mechanism. A drawback of the Matzain model is that it is based on experiments carried out only for South Pelto oil.

\subsection{Heat Analogy}

This is a proprietary model used in OLGA for wax deposition in pipelines. The model takes into account molecular diffusion, shear dispersion and shear stripping as mechanism of deposition. No further details of the model are provided in the manual of the software [15].

\section{Cold Flow Concepts for Wax Flow Assurance}

Three Cold Flow concepts were studied to assess their feasibility as flow assurance methods for control of wax deposition. They are: a non-insulated pipe section, a passive cooler with a bundle of parallel pipes and an active cooler. They consist on inducing, by cooling, the formation, precipitation and deposition of wax in a dedicated section of the production system. This section is then periodically "cleaned" and the inert wax particles are sent together with the production fluids. The criterion used to determine the length of the section is that the thickness of wax deposited at the end of the section has to be less than $1 \%$ of the total pipeline diameter. Practically, this occurs when the fluid reaches thermal equilibrium with the surroundings.

\subsection{Non-Insulated Pipe Section}

The non-insulated Pipe Section concept, Figure 1, consists in connect a pipe section without insulation (loop), at the beginning of the main transportation pipeline, cooled by sea currents [2] [3] [5]. The section must be long enough to ensure that all the wax is deposited there. This means that the fluid has to exit the loop at thermal equilibrium with the surroundings. Two pipe sections are placed in parallel so, when one has a significant amount of wax, it is then closed for wax removal, and the production fluids are diverted through the other section. During the wax removal, a pig crushes the wax accumulations on the wall 


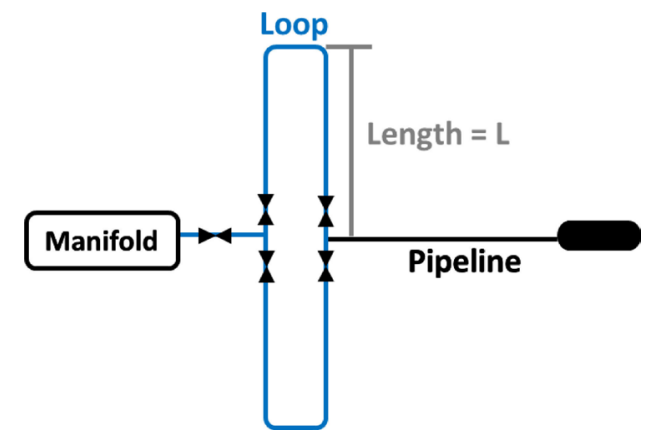

Figure 1. Non-insulated pipe section concept.

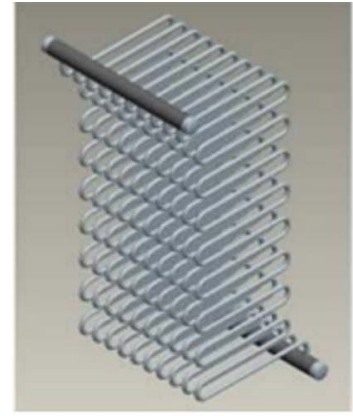

(a)

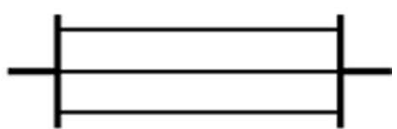

(b)

Figure 2. Passive cooler with a bundle of parallel pipes. (a) 3D isometric of a parallel pipe heat exchanger with natural cooling; (b) Modelling approximation.

and the residues are sent together with the flow in the main transportation line.

\subsection{Passive Cooler with a Bundle of Parallel Pipes}

This concept consists in installing a passive cooler, made of parallel pipe segments, cooled by sea currents (Figure 2). The wax will deposit in the walls of the cooler. To eliminate the wax, the heat exchanger can be pigged or its walls can be heated [20]. A feasibility study was performed where the number of parallel segments in the cooler and their length were the studied parameters. The aim was to find a combination were a thermodynamic equilibrium between the fluid and the surroundings were guaranteed at the outlet of the heat exchanger.

\subsection{Active Cooler}

This concept consists in connecting an active heat exchanger at the beginning of the system. The goal is to find the minimum duty needed to cool down the fluid until it reaches the temperature of the surroundings. This concept is the most difficult to pig, since the typical active heat exchangers are shell and tubes and the geometry is significantly more complex than the other two cases.

\section{Cases}

The study was divided in 3 cases, each one representing one cold flow concept. Additionally, a base case representing the original production system was created. The original production pipeline has a horizontal length of $8 \mathrm{~km}$, with 
an internal diameter of 6.69 inches. The fluid enters the pipeline with a mass flow of $17.51 \mathrm{~kg} / \mathrm{s}$, which represents a standard flow rate of $14 \times 10^{3} \mathrm{Sm}^{3} / \mathrm{d}$ for 32 API, a gas specific gravity of 0.95 , a temperature of $70^{\circ} \mathrm{C}$, a water cut of zero, a GVF of 0.085 and a WAT of $22^{\circ} \mathrm{C}$. The outlet pressure was 25 bara. The surrounding temperature was $4^{\circ} \mathrm{C}$. The external coefficient of convective heat transfer with seawater is $500 \mathrm{~W} / \mathrm{m}-\mathrm{K}$. Figure 3 shows a sketch of the flowline diagram used in OLGA.

Three layers compose the pipeline wall: steel, concrete and polypropylene. Their properties are given in Table 1.

The wax deposition model used was RRR. The simulation time was 90 days, with a maximum time step of $1000 \mathrm{~s}$ and a minimum of $1 \mathrm{~s}$. The information given above was used for all the cold flow cases.

\subsection{Case 1: Non-Insulated Pipe Section}

A sensitivity study to determine the required length of the pipe section (cooling length) was performed for three different subcases:

Case 1.1: Influence of the external convective coefficient of heat transfer. The required cooling length of the pipe section was found for several values of convective coefficient of heat transfer. The values used were within the range of expected free convection coefficients for water [21], and are given in Table 2.

Case 1.2: Influence of pipe diameter. The required pipe section length was determined for different values of pipe diameter (Table 2).

Case 1.3: Influence of watercut. Three values of watercut were studied in this subcase (Table 2).

Since OLGA is a $1 \mathrm{D}$ software, the pipe section was modelled as an equivalent pipeline section attached at the beginning of the original production system described on the base case. This means that the length of the equivalent pipe section is two times the length of the loop (Figure 4).

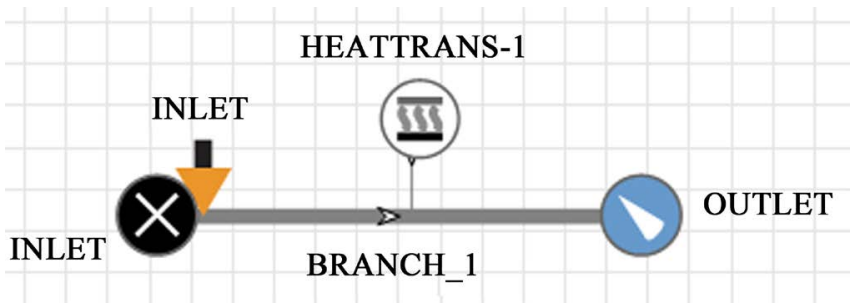

Figure 3. Schematic flowline diagram used in OLGA.

Table 1. Wall material properties.

\begin{tabular}{cccc}
\hline & Steel & Concrete & Poly-Propylene \\
\hline Thickness $(\mathrm{cm})$ & 1 & 0.6 & 0.30 \\
Conductivity $(\mathrm{W} / \mathrm{m}-\mathrm{K})$ & 50 & 1.7 & 0.12 \\
Density $\left(\mathrm{kg} / \mathrm{m}^{3}\right)$ & 7850 & 2250.0 & 960.00 \\
Capacity $(\mathrm{J} / \mathrm{kg}-\mathrm{K})$ & 485 & 880.0 & 1675.00 \\
\hline
\end{tabular}


Table 2. Sensitivity variables values used for Case 1 .

\begin{tabular}{ccc}
\hline Case 1.1 & Case 1.2 & Case 1.3 \\
\hline Convective coefficient $\left(\mathrm{W} / \mathrm{m}^{2}-\mathrm{C}\right)$ & Pipe diameter(in) & Watercut $(-)$ \\
\hline 500 & 6.69 & 0.00 \\
1000 & 8 & 0.15 \\
2000 & 9 & 0.30 \\
3000 & 10 & \\
& 11 & \\
\hline
\end{tabular}

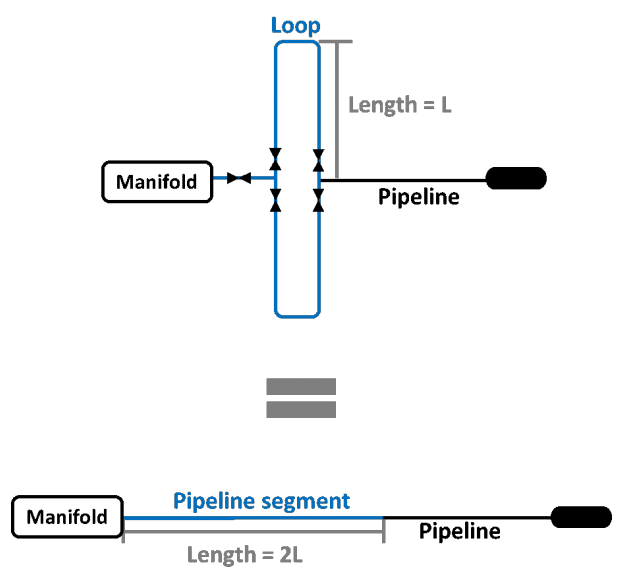

Figure 4. Equivalent one-dimensional loop used in OLGA simulations.

In this case, the equivalent $1 \mathrm{D}$ pipe section does not have insulation. This means that its wall consists only of one material, steel, with a thickness of $1 \mathrm{~cm}$. The rest of the pipeline has the configuration mentioned in the base case.

\subsection{Case 2: Passive Cooler with a Bundle of Parallel Pipes}

As mentioned earlier, for this case two sensitivity variables were taken into account. The first one was the number of cooler parallel segments and, the second one, their length. In the same way as case 1 , this case was divided into two sub-cases, the first model the cooler with two parallel segments (case 2.1), and the second use three parallel segments (case 2.2). Figure 5 shows a sketch of the model for case 2.2 in OLGA.

In both subcases, the fluid is distributed evenly through all the parallel segments and the distance between segments is $1 \mathrm{~m}$ (FLOWPATH_2 and FLOWPATH_3 in Figure 5). The cooler pipes diameter is 3 inches and the wall material is steel with thickness of $0.4 \mathrm{~cm}$ without insulation.

\subsection{Case 3: Active Cooler}

Here, a heat exchanger was added to the system, and the minimum duty to avoid wax deposition in the pipeline was determined. Unlike the other cases, in case 3 , 
external forced convection is used to cool down the flow to ensure the fluid leaves the heat exchanger at thermal equilibrium with the surroundings.A sketch of the model is shown in Figure 6.

\section{Results}

The criteria used to determine the loop length for Case 1 was that the wax thickness at the end of the loop had to be at least $1 \%$ of the pipeline diameter after a production of 90 days. Figure 7 shows the required cooling length that meets the criteria in each subcase. Additionally, the added pressure drop and the wax thickness profile for all the subcases are given in Figure 8 and Figure 9, respectively. For all cases, the added pressure drop was calculated with Equation (4). In general, all cases required a loop length of at least $3 \mathrm{~km}$ to allow most of the wax to deposit in the section.

$$
\text { Added Pressure Drop [\%] }=\frac{\Delta p_{\text {base case }}-\Delta p_{\text {new }}}{\Delta p_{\text {base case }}}
$$

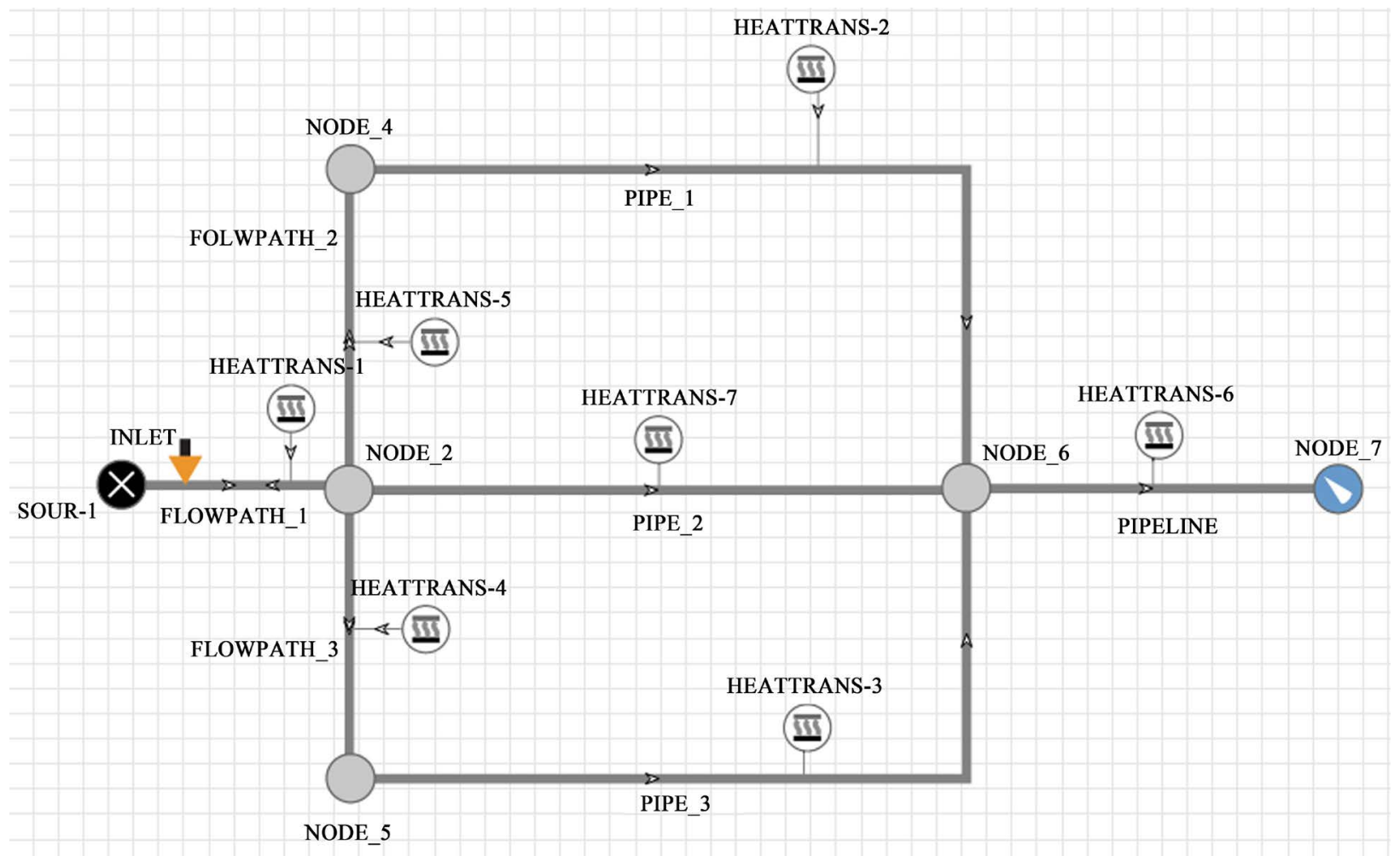

Figure 5. Schematic diagram of Case 2 used in OLGA.

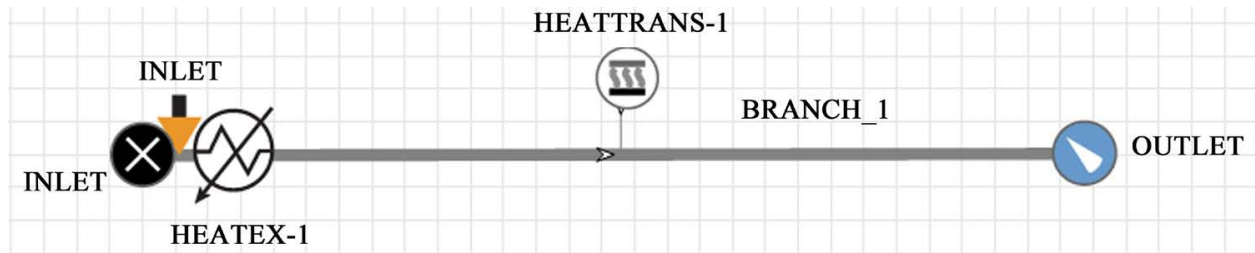

Figure 6. Schematic diagram of Case 3 used in OLGA. 


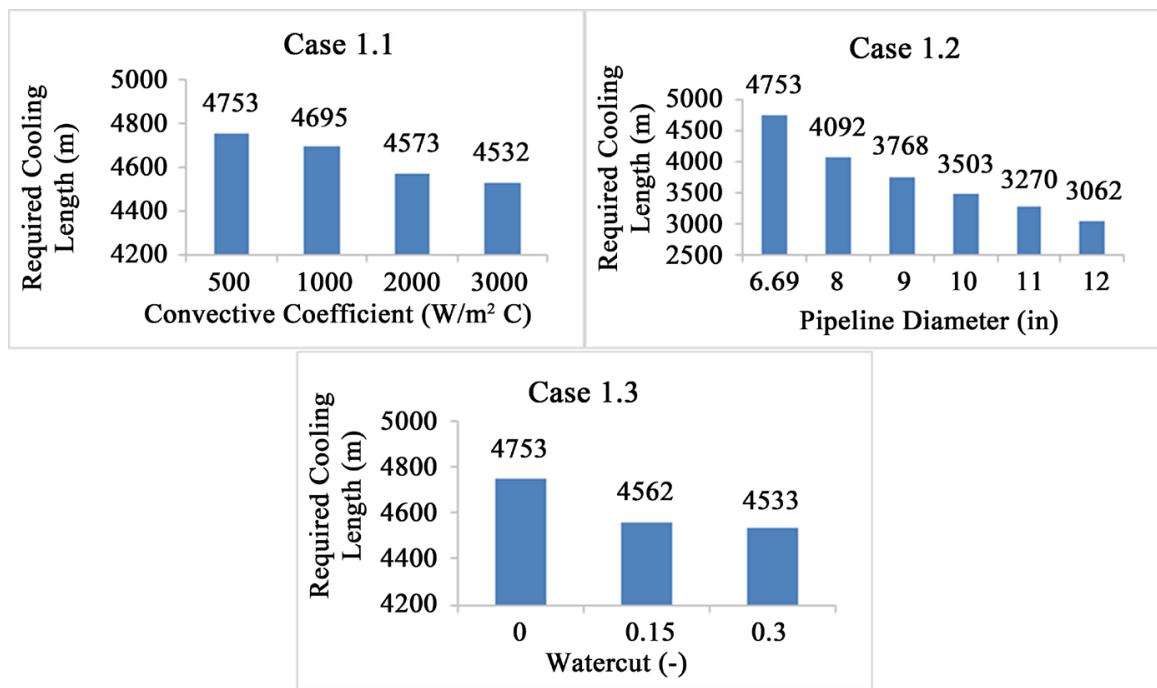

Figure 7. Required cooling length for Case 1 after 90 days of production.
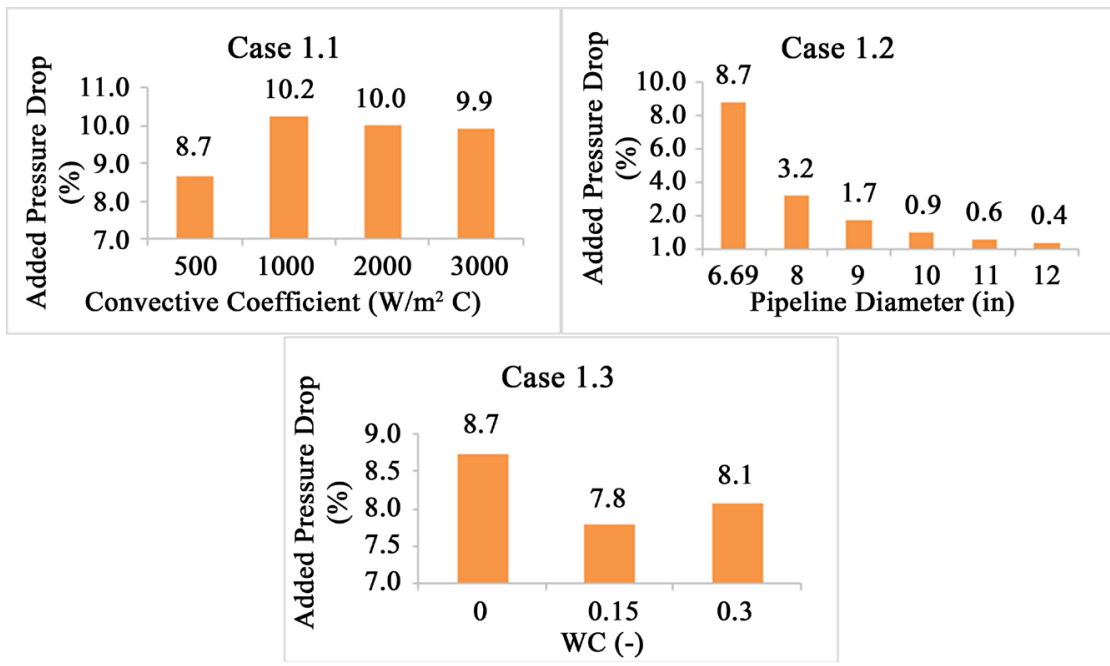

Figure 8. Added pressure drop for Case 1 after 90 days of production.
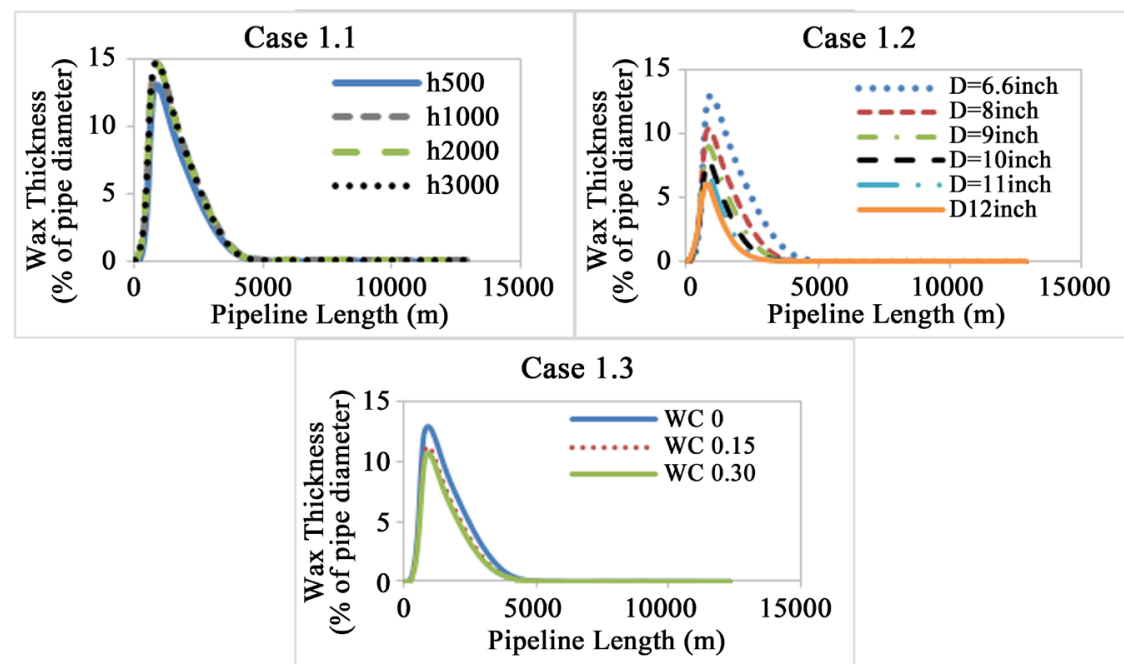

Figure 9. Wax thickness profile for Case 1 after 90 days of production. 
Figure 7 to Figure 9 show that the pipeline diameter has the biggest influence in the required length of the non-insulated pipe section. According to the results of the sensitivity analysis performed in subcase 1.2, the biggest diameter provides also the smaller cooling length, pressure drop and maximum wax thickness. With bigger diameter, the heat transfer, between the bulk flow and the surroundings, is larger and the required cooling length is smaller. An increase in pipe diameter from 6.69 in (base case diameter) to 12 in (maximum diameter studied) give a decrease in the required cooling length of $35.58 \%$ (from $4753 \mathrm{~m}$ to $3062 \mathrm{~m}$ ) and in the added pressure drop of $95.40 \%$ (from $8.7 \%$ of added pressure for a diameter of 6.69 in to $0.4 \%$ of added pressure for a diameter of 12 in).

Changes in the outer convective coefficient and stream watercut do not have much influence in the required cooling length, but the watercut has a smaller influence in the added pressure drop than the convective coefficient. An increment in the convective coefficient of $2500 \mathrm{~W} / \mathrm{m}^{2} \mathrm{C}$, decreases the required cooling length in $4.65 \%$, but increases the pressure drop of $1.2 \%$. In the other hand, a water cut of $30 \%$ gives a decrease of $4.63 \%$ in the required cooling length and of $0.6 \%$ in the pressure drop.

An important conclusion from the feasibility study performed on Case 1 is that this technology is more attractive to long transportation distances $(>50 \mathrm{~km})$. For example, comparing with the system used here ( $8 \mathrm{~km}$ pipeline), the minimal cooling length obtained (Case 1.2, using a 12 inches diameter pipeline) represents $38.28 \%$ of the original production pipeline, while for a pipeline of 50 $\mathrm{km}$, would represent only $6.12 \%$.

The results shown in this section might depend strongly on the fluid characteristics, rates and pipeline dimensions. Thus, direct extrapolation of these observations to other subsea production systems is not recommended.

Figure 10 and Figure 11 show the results obtained for Case 2. Here, the number of cooler segments has a big influence in their required cooling length. For two segments, the length was $2.3 \mathrm{~km}$, which represents $28.75 \%$ of the original production system. While, for three segments the length was $1.6 \mathrm{~km}$, representing $20 \%$ of the original production system. This means that, with the parallel pipe passive cooler (case 2) the space needed can be much less than that needed for the non-insulated pipe section (case 1). However, a disadvantage is that the added pressure drop needed will be bigger in comparison with that of the non-insulated pipe section, this is due to the smaller diameter pipes use in the cooler, yet this pressure will decrease with the increase of the number of cooler segments.

For Case 3, a heat exchanger was connected at the beginning of the production system. Here the required duty that guarantee thermal equilibrium between the production fluid and the surrounding was 2.2 MW. To compare, a subsea heat exchanger with forced cooling advertised by the company NOV have a typical cooling capacity of 10 to $20 \mathrm{MW}$ per unit [22]. The added pressure drop was 0.61 bara, this value is without taking into account the pressure loss through the 


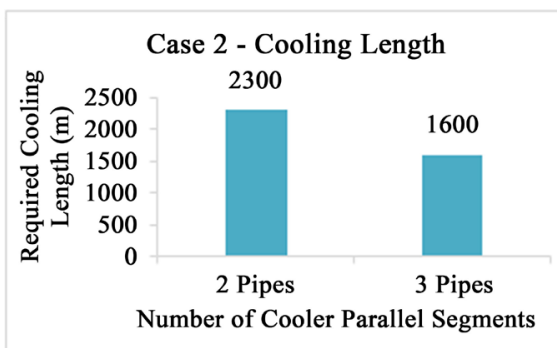

(a)

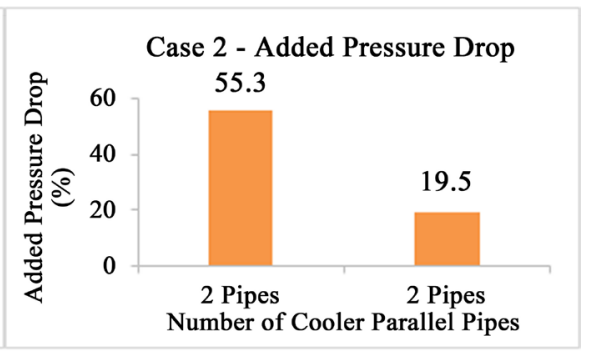

(b)

Figure 10. Results for Case 2 after 90 days of production (a) required cooling length, (b) added pressure drop.
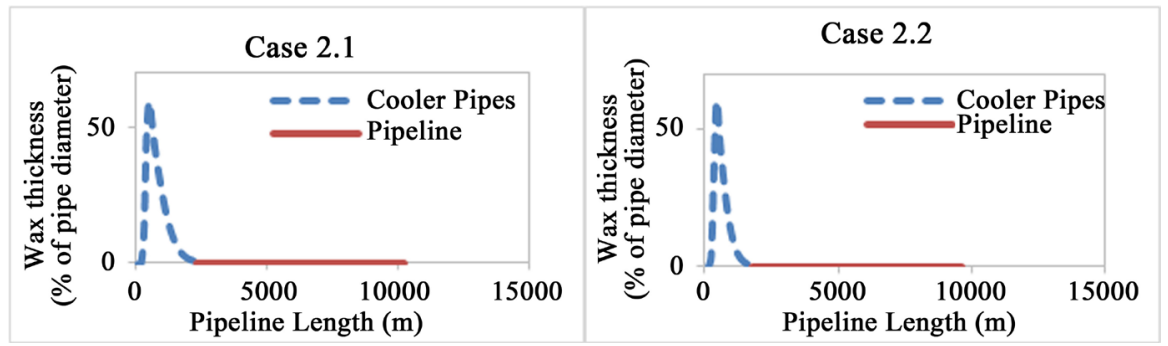

Figure 11. Wax thickness profile for Case 2 after 90 days of production.

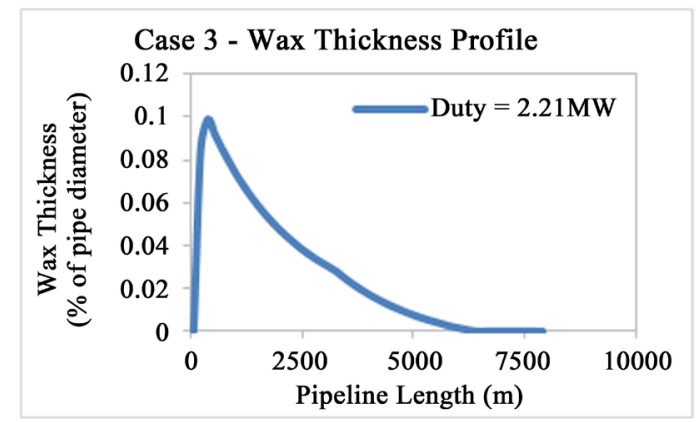

Figure 12. Wax thickness profile for Case 3 after 90 days of production.

heat exchanger. This case is the more efficient to control wax deposition, however is the less friendly for pigging due to the complex structure of heat exchangers. Figure 12 shows the wax thickness profile for Case 3 after 90 days of production.

\section{Conclusions}

- Three wax cold flow concepts were successfully studied for installation at the upstream end of the main transportation pipeline. The three concepts are: a non-insulated pipe section, a parallel pipe heat exchanger with natural cooling and a heat exchanger with forced cooling. The analysis was performed with a commercial 1D mechanistic multiphase flow simulator.

- For the non-insulated pipe section concept, the required length of the loop was at least $3 \mathrm{~km}$, which can be impractical for some production systems. For most cases, the added pressure drop due to the presence of the loop was negligible (around 10\%). 
- When using a passive cooler with a bundle of parallel pipes the required length for cooling was reduced considerably (30\% - 50\%) compared with the case 1 . However, the lengths and diameters required might still be too large for placing them inside a compact subsea structure. Another drawback of this concept is that the cooler uses smaller pipe diameters, which means that the pressure drop will increase and the pipe will get block in shorter times, needing to be cleaned often.

- In the active cooler case, the minimal duty obtained was comparable with subsea heat exchangers advertised by a manufacturer. The disadvantage of this concept is that it is difficult to pig due to the complexity of the equipment and the added pressure drop. The authors didn't perform a review or studied methods to remove wax in such equipment. However, the following reference [20] is given as a possible solution.

\section{References}

[1] Coberly, C. (1942) Method of Preventing Wax Deposits in Tubing. US Patent No. 2303823 A.

[2] Merino-Garcia, D. and Correra, S. (2008) Cold Flow: A Review of a Technology to Avoid Wax Deposition. Taylor \& Francis Group, Ed, 26, 446-459. https://doi.org/10.1080/10916460600809741

[3] Al-Yaari, M. (2011) Paraffin Wax Deposition: Mitigation \& Removal Techniques. SPE Saudi Arabia Section Young Professionals Technical Symposium, Dhahran, 14-16 March 2011, SPE-155412-MS.

[4] Berson, R.A. (2000) Method for Making Slurry. US Patent No. 6070417 A.

[5] Fung, G., Amin, R., Fleyfel, F. and O’Sullivan, J. (2003) Method for Reducing Solids Buildup in Hydrocarbon Steams Produced from Wells. US Patent No. 6656366 B1.

[6] Nenniger, J. (1991) Process for Inhibiting Formation of Wax Deposits. CA Patent No. 1289497 C.

[7] Knowles, W.T. (1987) Choke Cooling Waxy Oil. US Patent No. 4697426 A.

[8] Watson, M.J., Speranza, A. and LaCombe, M. (2015) Rigorous Integrated Production Modelling of Cold Flow Technology. Offshore Technology Conference Brazil. Rio de Janeiro, 27-29 Ctober 2015, OTC-26291-MS.

[9] Larsen, R., Lund, A. and Argo, C.B. (2003) Cold Flow-A Practical Solution. 11 ${ }^{\text {th }}$ International Conference on Multhiphase Flow "Multiphase 03" BHR Group, San Remo, 11-13 June 2003.

[10] Gudmundsson, J.S. (2002) Cold Flow Hydrate Technology. $4^{\text {th }}$ International Conference on Gas Hydrates, Yokohama, 19-23 May 2002, 5 p.

[11] Azarinezhad, R., Chapoy, R., Anderson, R. and Tohidi, B. (2008) HYDRAFLOW: A Multiphase Cold Flow Technology for Offshore Flow Assurance Challenges. 2008 Offshore Technology Conference, Houston, Texas, 5-8 May 2008, OTC-19485-MS. https://doi.org/10.4043/19485-MS

[12] Akpabio, M.G. (2013) Cold Flow in Long Distance Subsea Pipelines. Master Thesis, NTNU, Trondheim.

[13] Vinatovskaja, E. (2015) Cold Flow in the Arctic: A Feasibility Study. Master Thesis, University of Stavanger, Stavanger.

[14] Kondapi, P. and Moe, R. (2013) Today's Top 30 Flow Assurance Technologies: 
Where Do They Stand? Offshore Technology Conference, Houston, Texas, 6-9 May 2013, OTC-24250-MS.

[15] Olga (2012) User Manual.

[16] Rosvol, K. (2008) Wax Deposition Model. Master Thesis, NTNU, Trondheim.

[17] Burger, E.D., Perkins, T.K. and Striegler, J.H. (1981) Studies of Wax Deposition in the Trans Alaska Pipeline. Journal of Petroleum Technology, 33, 1075-1086. https://doi.org/10.2118/8788-PA

[18] Bern, P.A., Withers, V.R. and Cairns, J.R. (1980) Wax Deposition in Crude Oil Pipelines. European Offshore Petroleum Conference and Exhibition, London, UK, 21-24 October 1980, SPE-206-1980-MS. https://doi.org/10.2118/206-1980-MS

[19] Brown, T.S., Niessen, V.G. and Erickson, D. (1993) Measurement and Prediction of the Kinetics of Paraffin Deposition. 68th Annual Technical Conference and Exhibition of the Society of Petroleum Engineers, Houston, 3-6 October 1993, SPE-26548-MS. https://doi.org/10.2118/26548-MS

[20] Empig (2017). http://empig.no/technology/

[21] Bergman, T., Lavine, A., Incropera, F. and Dewitt, D. (2011) Fundamentals of Heat and Mass Transfer. 7th Edition, John Wiley and Sons, Jefferson City.

[22] NOV (2017).

http://www.nov.com/Segments/Completion_and_Production_Solutions/Subsea_Pr oduction_Systems/Subsea_Cooling.aspx 